\title{
PERLINDUNGAN HUKUM BAGI PEMEGANG HAK ATAS TANAH DALAM KASUS TUMPANG TINDIH KEPEMILIKAN ATAS SEBIDANG TANAH DI BADAN PERTANAHAN NASIONAL/ATR KABUPATEN KUDUS
}

\author{
Kuswanto \\ Mahasiswa Program Magister (S2) Kenotariatan UNISSULA \\ email : kuswantopu@gmail.com
}

Akhmad Khisni

Dosen Fakultas Hukum UNISSULA

\begin{abstract}
ABSTRAK
Tesis ini bertujuan untuk mengetahui cara penerbitan sertipikat baru juga permasalahan hak atas tanah yang melebihi tanah dari tetangga batasnya, dalam penelitian ini dilakukan wawancara langsung dengan responden serta nara sumber untuk memperoleh data dalam penyusunan penelitian ini, tetapi juga dengan menggambarkan keadaan obyek yang diteliti.

Prosedur terbitnya sertipikat baru dengan ketentuan undang-undang pokok agraria yaitu PPAT/pemohon membawa dan memberikan berkas yang diminta oleh Badan Pertanahan Nasional/ATR untuk didaftarkan ke loket juga membayar ke Bendahara berdasarkan PP No. 46 tahun 2002 berbunyi tarif biaya pendaftaran tanah di BPN. Selanjutnya dilakukan pengukuran tanah, apabila ada pengalihan hak maka disertakan juga akta yang dibuat oleh PPAT berdasarkan peta bidang yang sudah dicetak BPN, tetapi apabila tidak ada peralihan hak maka bisa langsung diproses pembuatan sertipikat di BPN, dalam kurun waktu \pm 8 (delapan) bulan, sertipikat tersebut bisa diambil di BPN. Penyebab tumpang tindih kepemilikan hak atas sebidang tanah di Badan Pertanahan Nasional / ATR Kabupaten Kudus dengan adanya pihak BPN tidak teliti dalam rangka penerbitan Sertipikat dan tidak cermat melihat arsip peta bidang pendaftaran tanah sebelumnya, juga sebagai Pemilik/Pemegang Hak Atas Tanah lalai dalam memberikan patok-patok batas bidang tanah yang dimiliki berdasarkan PP RI No. 24 Tahun 1997 Pasal 17 ayat (3). Perlindungan hukum terhadap para pemegang hak atas tanah bilamana terjadi tumpang tindih kepemilikan sebidang tanah tercantum dalam Peraturan Pemerintah Nomor 24 Tahun 1997, beberapa Pasal 19 ayat (2) huruf c, dan Pasal 23 ayat (2), juga Pasal 32 ayat (2) serta Pasal 38 ayat (2) UUPA, yang berbunyi surat-surat tanda bukti hak berlaku sebagai alat pembuktian yang kuat demikian juga Pemegang hak atas tanah yang menjadi obyek sengketa tidak mendapatkan perlindungan hukum setelah adanya keputusan pencabutan atas sertipikat tanah tersebut.
\end{abstract}

Kata Kunci : Leter C Desa, Surat Ukur, Sertipikat Asli.

\section{A. PENDAhuluan}

\section{Latar Belakang}

Tanah merupakan karunia Tuhan Yang Maha Esa, atas dasar hak menguasai dari negara. Bahkan tak jarang pula banyak beredar sertipikat hak atas tanah yang samping tanahnya ikut disertipikatkan sebagian sehingga terjadi istilah " Sertipikat Tumpang Tindih ". Pendaftaran tanah meliputi : pengukuran, pemetaan dan pembukuan tanah, pendaftaran hak-hak atas tanah dan peralihannya, pemberian surat tanda bukti hak yang berlaku sebagai alat pembuktian yang kuat (Pasal 19 UUPA: UU Nomor 5 Tahun 1960). maka diselenggarakan pendaftaran tanah diseluruh wilayah Republik Indonesia. ${ }^{1}$

Gambaran kasus sengketa tumpang tindih tersebut yakni tanah pekarangan milik tuan Kasmono dan ibu Maryatun yang tercatat dalam Sertipikat Hak Milik (SHM) Desa Karangbener Nomor 1678 dengan

\footnotetext{
$1 \quad$ http://www.kalimantanpost.com/opini/publik/794Pendaftaran-tanah-dalam-rangka-kepastian-hukum.html, diakses pada tanggal 26 Desember 2016
}

salah satu pihak tetangganya yang merupakan tanah pekarangan milik tuan Mohamad Roekan tercatat dalam sertipikat Hak Milik Desa Karangbener Nomor 2807 atas nama Mohamad Roekan seluas 333 m2 (tigaratus tigapuluh tiga meter persegi).

Berdasarkan gambaran kasus tersebut, sertipikat obyek sengketa tersebut diuraikan dengan latar belakang tersebut diatas maka penelitian ini diangkat menjadi judul penelitian tentang : "Perlindungan Hukum Bagi Pemegang Hak Atas Tanah Dalam Kasus Tumpang Tindih Kepemilikan Atas Sebidang Tanah Di Badan Pertanahan Nasional / ATR Kabupaten Kudus".

\section{Perumusan Masalah}

a. Bagaimana Prosedur Terbitnya Sertipikat Baru Dengan Ketentuan Undang-Undang Pokok Agraria?

b. Faktor-Faktor Apa Saja Yang Menyebabkan Tumpang Tindih Kepemilikan Hak Atas Sebidang Tanah di Badan Pertanahan Nasional / ATR Kabupaten Kudus? 
c. Bagaimanakah Perlindungan Hukum Terhadap Para Pemegang Hak Atas Tanah Bilamana Terjadi Tumpang Tindih Kepemilikan Sebidang Tanah?

\section{B. Pembahasan}

1. Prosedur Terbitnya Sertipikat Baru Dengan Ketentuan Undang-Undang Pokok Agraria

Pemohon melengkapi semua persyaratan yang diminta oleh Badan Pertanahan Nasional/ATR Kabupaten Kudus. Selanjutnya pihak PPAT/pemohon mendaftarkan ke loket BPN dan membayar biaya, yang mengacu pada PP No. 46 tahun 2002 tentang tarif dan biaya pendaftaran tanah. Pemohon/PPAT menunggu BPN untuk pengukuran tanah, apabila ada pengalihan hak maka disertakan akta yang dibuat oleh PPAT untuk peralihan hak berdasarkan peta bidang yang sudah keluar, tetapi apabila tidak ada peralihan hak maka langsung untuk diproses pembuatan sertipikatnya di BPN dalam kurun waktu \pm 8 (delapan) bulan sertipikat sudah selesai diproses dan bisa diambil di Kantor Badan Pertanahan Nasional/ATR Kabupaten Kudus. Sertipikat Sudah jadi Rangkap dua: satu rangkap disimpan di kantor BPN sebagai buku tanah, dan satu rangkap dipegang seseorang sebagai tanda bukti kepemilikan atas tanah dan bangunan. Arsip buku tanah tercantum data detail mengenai tanah, mencakup data fisik maupun data yuridis ${ }^{2}$.

Agar lebih jelasnya tentang prosedur penerbitan sertipikat UUPA penulis sajikan dalam Bagan/Skema dibawah ini :

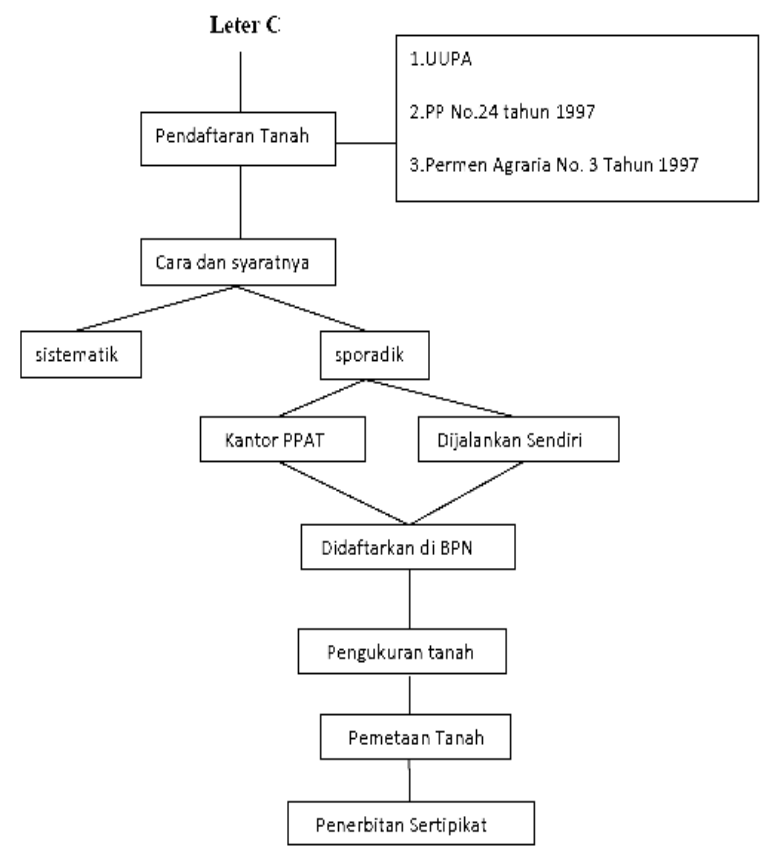

\footnotetext{
${ }^{2}$ https://www.cermati.com/artikel/cara-lengkap-mengurussertifikat-tanah-dan-biayanya, diakses pada tanggal 6 Pebruari 2017
}

2. Faktor-Faktor Yang Menyebabkan Tumpang Tindih Kepemilikan Hak Atas Sebidang Tanah Di Badan Pertanahan Nasional / ATR Kabupaten Kudus

Dalam kasus tumpang tindih tanah dari tanah yang bernama Bapak KASMONO, yang pada saat itu akan diadakan pemecahan 2 (dua) bidang tanah, yang ternyata dalam lapangan ada kekurangan ukuran batas dengan salah satu tetangga yang bernama bapak MOHAMAD ROEKAN batas utaranya sekaligus masih saudara yang tanah tersebut juga ikut dalam sertipikat bapak MOHAMAD ROEKAN ${ }^{3}$.

Asal mula pemilik dari samping yang bernama SURAHMI mengajukan proses pemecahan 4 (empat) bidang tanah, dilakukan pengukuran oleh pihak BPN Kabupaten Kudus, dan tetangga sampingnya pada waktu itu tidak ada batas-batas patok sampingnya, sehingga dari pihak mereka hanya ada rembuk batas dan disetujui oleh kedua belah pihak tanpa memeriksa lagi tanahnya terlebih dahulu batas-batas tanah tersebut, Bapak KASMONO tidak mengetahui kalau tanahnya yang sebenarnya berkurang, hanya menggunakan kepercayaan dan perkiraan saja pada waktu itu karena mereka masih saudara, akan tetapi tidak mengetahui kalau tanahnya berkurang dengan lebar 2 (dua) meter ${ }^{4}$.

Setelah bapak KASMONO ingin mengajukan pemecahan sertipikat menjadi 2 (dua) bidang, dan bapak KASMONO melalui Notaris dan PPAT Elizabeth Sri Indrawati, SH., terdapat informasi pada waktu pengukuran dilapangan terdapat sengketa tetangga batas kalau sebagian tanahnya samping kiri dan samping kanan kurang 2 meter sehingga dihitung kurangnya luas $\pm 80 \mathrm{~m} 2$, karena berkurang 2 meter dari kanan kiri, sedangkan bapak KASMONO merasa dirugikan terjadilah sengketa disitu

Karena pemohon bapak KASMONO lokasi yang dimohon tersebut tumpang tindih dengan tetangga sampingnya yang merupakan saudaranya yang masih termasuk keponakannya juga Bapak KASMONO maka dengan besar hati si pemilik tanah bapak KASMONO besar hati untuk mengikhlaskan dan bersedia menerima hasil sisa tanah dilapangan tersebut. Dengan cara mediasi tersebut dengan dihadiri banya saksi-saksi perangkat, petugas BPN permasalahan tumpang tindih bisa diselesaikan.

Agar lebih jelasnya faktor yang menghambat/kendala dalam penerbitan setipikat hak atas tanah sehingga menjadi sengketa penulis buat dalam tabel :

\footnotetext{
3 Berdasarkan Wawancara dengan Basrowi, Seksi Pengukuran BPN Kabupaten Kudus (Kudus, 1 Pebruari 2017)

4 Berdasarkan Wawancara dengan Kasmono, Pelaku dari pemilik tanah tersebut (Kudus, 4 Pebruari 2017)
} 


\begin{tabular}{|c|c|c|}
\hline No & Kendala & Solusi \\
\hline 1. & $\begin{array}{l}\text { Aparat penegak hukum } \\
\text { kurang cermat dan teliti } \\
\text { dalam proses pelaksanaan } \\
\text { pendaftaran yang pertama } \\
\text { kali, selain itu juga dari } \\
\text { pihak kantor desa yang } \\
\text { kemungkinan melakukan } \\
\text { penyimpangan yaitu unsur } \\
\text { kesengajaan dari Aparat } \\
\text { Desa apabila ada tanah } \\
\text { yang tidak diurus tanah } \\
\text { oleh pemiliknya tersebut, } \\
\text { dan Kepala Desa sudah } \\
\text { berganti ganti, }\end{array}$ & $\begin{array}{l}\text { Aparat penegak } \\
\text { hukum hendaknya } \\
\text { dalam } \\
\text { melaksanakan } \\
\text { pendaftaran } \\
\text { pertama kali } \\
\text { dengan benar } \\
\text { berdasarkan } \\
\text { Undang-undang } \\
\text { yang berlaku, dan } \\
\text { Aparat Desa atau } \\
\text { pun Kepala Desa } \\
\text { memberikan data } \\
\text { yang sebenarnya } \\
\text { sesuai dengan } \\
\text { data yang ada. }\end{array}$ \\
\hline 2. & $\begin{array}{l}\text { Hambatan yang dihadapi } \\
\text { oleh Kantor } \\
\text { Pertanahan terhadap } \\
\text { masyarakat adalah } \\
\text { - Dalam pengukuran, } \\
\text { diadakan pengukuran yang } \\
\text { pertama kali para tetangga } \\
\text { pemilik tanah yang ada di } \\
\text { sebelah-sebelah tanah } \\
\text { pemilik tanah yang diukur } \\
\text { tidak hadir turut } \\
\text { menyaksikan pengukuran. } \\
\text { - Pemilik tidak menjaga } \\
\text { patok } \\
\text { - Tanda batas yang tidak } \\
\text { dirawat dan hilang dapat } \\
\text { menimbulkan sengketa- } \\
\text { sengketa batas dan } \\
\text { sengketa kepemilikan atau } \\
\text { penguasaan tanah di } \\
\text { kemudian hari }\end{array}$ & $\begin{array}{l}\text { Setelah adanya } \\
\text { pengukuran untuk } \\
\text { langsung di beri } \\
\text { patok beton } \\
\text { sehingga patok } \\
\text { tidak akan hilang, } \\
\text { dan tidak akan } \\
\text { jadi sengketa } \\
\text { dikemudian hari. }\end{array}$ \\
\hline 3. & $\begin{array}{l}\text { Penguasaannya oleh orang } \\
\text { perseorangan } \\
\text { atau badan hukum tidak } \\
\text { menggunakan tanah } \\
\text { tersebut sesuai keadaannya } \\
\text { atau menurut sifat dan } \\
\text { tujuan pemberian haknya, } \\
\text { atau tidak memeliharanya } \\
\text { dengan baik, } \\
\text { diterlantarkan, }\end{array}$ & $\begin{array}{l}\text { Dalam } \\
\text { penguasaan tanah } \\
\text { pemilik tanah } \\
\text { menggunakan } \\
\text { tanah berdasarkan } \\
\text { fungsinya } \\
\text { misalnya sawah } \\
\text { tidak boleh dibuat } \\
\text { perumahan, atau } \\
\text { dikavlingkan } \\
\text { untuk kepentingan } \\
\text { pribadi. }\end{array}$ \\
\hline
\end{tabular}

3. Perlindungan Hukum Terhadap Para Pemegang Hak Atas Tanah Bilamana Terjadi Tumpang Tindih Kepemilikan Sebidang Tanah.

Pemberian kepastian hukum di bidang pertanahan ini, memerlukan tersedianya perangkat hukum yang tertulis, lengkap dan jelas yang dilaksanakan secara konsisten sesuai dengan jiwa dan isi ketentuan-ketentuannya.

Pada saat ini, kebanyakan sengketa pertanahan dalam hal ini sertifikat tumpang tindih diselesaikan melalui 3 (tiga) cara, yaitu ${ }^{5}$ :

a. Penyelesaian secara langsung oleh pihak dengan musyawarah

Dasar musyawarah untuk mufakat tersirat dalam pancasila sebagai dasar kehidupan bermasyarakat Indonesia dan dalam UUD 1945. Musyawarah dilakukan diluar pengadilan dengan atau tanpa mediator. Mediator biasanya dari pihak-pihak yang memiliki pengaruh misalnya Kepala Desa/Lurah, ketua adat serta pastinya Badan Pertanahan Nasional.

b. Melalui arbitrase dan alternative penyelesaian sengketa kesepakatan yang dibuat dalam bentuk tertulis dan disetujui oleh para pihak.

c. Penyelesaian sengketa melalui badan peradilan.

Selain itu, Pasal 32 ayat (1) Peraturan Pemerintah Nomor 24 Tahun 1997 menyatakan bahwa "Sertipikat merupakan tanda bukti hak yang berlaku sebagai alat pembuktian yang kuat mengenai data fisik dan data yuridis yang termuat di dalamnya, sepanjang data fisik dan data yuridis tersebut sesuai dengan yang ada dalam surat ukur dan buku tanah yang bersangkutan".

Dalam penyelesaian persoalan maka segala hal yang seharusnya menjadi wewenang pengadilan ditempatkan di bawah kekuasaan administratif ${ }^{6}$.

Penyelesaian sengketa dan konflik kasus pertanahan yang terjadi dapat diselesaikan dan dikelompokkan menjadi 2 yaitu ${ }^{7}$ :

a) Penyelesaian melalui jalur hukum/pengadilan, meliputi :

- Para pihak harus mengajukan gugatan ke pengadilan

- Diselenggarakan tertib administrasi di bidang pertanahan.

b) Penyelesaian melalui proses pelaksanaan mediasi.

\section{Penutup}

\section{Kesimpulan}

Berdasar uraian di atas dapat diambil kesimpulan sebagai berikut:

a. Prosedur Terbitnya Sertipikat Baru Dengan Ketentuan Undang-Undang Pokok Agraria : pemohon melengkapi semua persyaratan yang

${ }^{5}$ Elza Syarief, 2012, Menuntaskan Sengketa Tanah Melalui Pengadilan Khusus Pertanahan, Cetakan Petama, PT. Gramedia, Jakarta, hlm.375

6 Abdurrahman, 1983, Beberapa Aspek Hukum Agraria, Alumni, Bandung, hal.92

7 Yuyun Mintaraningrum, Aspek Kepastian Hukum Dalam Penerbitan Sertifikat Hak Tanah, Jurnal Repertorium, ISSN:2355-2646, Volume II No. 2 Juli - Desember 2015 
diminta oleh Badan Pertanahan Nasional/ATR Kabupaten Kudus. Selanjutnya pihak PPAT/ pemohon mendaftarkan ke loket BPN dan membayar biaya, yang mengacu pada PP No. 46 tahun 2002 tentang tarif dan biaya pendaftaran tanah. Pemohon/PPAT menunggu BPN untuk pengukuran tanah, apabila ada pengalihan hak maka disertakan akta yang dibuat oleh PPAT untuk peralihan hak berdasarkan peta bidang yang sudah keluar, tetapi apabila tidak ada peralihan hak maka langsung untuk diproses pembuatan sertipikatnya di BPN dalam kurun waktu \pm 8 (delapan) bulan sertipikat sudah selesai diproses dan bisa diambil di Kantor Badan Pertanahan Nasional/ATR Kabupaten Kudus.

b. Faktor-Faktor Yang Menyebabkan Tumpang Tindih Kepemilikan Hak Atas Sebidang Tanah Di Badan Pertanahan Nasional / ATR Kabupaten Kudus yaitu faktor dari kantor pertanahan berupa tidak teliti dan tidak cermat dalam mengadakan penyelidikan riwayat bidang tanah dan pemetaan batas-batas bidang kepemilikan tanah dalam rangka penerbitan Sertipikat obyek sengketa; dan Pertanahan tidak melakukan penelitian atau melihat gambar peta pendaftaran tanah yang dimiliki, faktor dari Pemilik/Pemegang Hak Atas Tanah yaitu para pemilik tanah sertipikat yang pertama dengan pemilik tanah yang lain dan tidak memberikan patok-patok batas bidang tanah yang dikuasainya seperti yang diatur dalam PP RI No. 24 Tahun 1997 Pasal 17 ayat (3), sehingga menimbulkan kasus penguasaan tanah secara tumpang tindih.

c. Perlindungan Hukum Terhadap Para Pemegang Hak Atas Tanah Bilamana Terjadi Tumpang Tindih Kepemilikan Sebidang Tanah yaitu sebagaimana dalam Peraturan Pemerintah Nomor 24 Tahun 1997, dan Pasal 19 ayat (2) huruf c, Pasal 23 ayat (2), Pasal 32 ayat (2) dan Pasal 38 ayat (2) UUPA, bahwa surat-surat tanda bukti hak berlaku sebagai alat pembuktian yang kuat dan Pemegang hak atas tanah yang menjadi obyek sengketa tidak mendapatkan perlindungan hukum setelah adanya keputusan pencabutan atas sertipikat tanah tersebut karena menganut sistem publikasi dalam pendaftaran tanah yaitu sistem publikasi negatif (tidak mutlak) yang mengandung unsur positif.

\section{Saran-Saran}

1. Kepada Pemerintah dalam pendaftaran tanah menggunakan sistem publikasi positif sehingga pemegang hak atas tanah benar-benar mendapat perlindungan yang mutlak atas kepemilikan sertipikat hak milik atas tanah tersebut dan tidak dapat diganggu gugat kembali.

2. Sebagai pejabat Kantor Badan Pertanahan Nasional/ATR Kabupaten Kudus lebih meningkatkan upaya pencegahan tumpang tindih atas penerbitan sertipikat hak atas tanah dengan melakukan pendaftaran tanah dengan lebih teliti, cermat dan seksama terutama pada saat melakukan pengukuran dan pemetaan, benar-benar ditanya dan dicari batas-batas tanah yang sebenarnya.

3. Untuk Masyarakat supaya memberikan keterangan yang benar batas-batas tanah, dan pemilik tanah diharuskan langsung memasang patoknya dengan benar berupa beton dan kuat agar tidak hilang batas-batas tanahnya.

\section{DAFTAR PUSTAKA}

Abdurrahman, 1983, Beberapa Aspek Hukum Agraria, Alumni, Bandung

Elza Syarief, 2012, Menuntaskan Sengketa Tanah Melalui Pengadilan Khusus Pertanahan, Cetakan Petama, PT. Gramedia, Jakarta

Yuyun Mintaraningrum, Aspek Kepastian Hukum Dalam Penerbitan Sertifikat Hak Tanah, Jurnal Repertorium, ISSN:2355-2646, Volume II No. 2 Juli - Desember 2015

Berdasarkan Wawancara dengan Basrowi, Seksi Pengukuran BPN Kabupaten Kudus

Berdasarkan Wawancara dengan Kasmono, Pelaku dari pemilik tanah tersebut

http://www.kalimantanpost.com/opini/publik/794Pendaftaran-tanah-dalam-rangka-kepastianhukum.html

https://www.cermati.com/artikel/cara-lengkapmengurus-sertifikat-tanah-dan-biayanya 